\title{
Risk profiles of infants $\geq 32$ weeks' gestational age with oropharyngeal and oesophageal dysphagia in neonatal care
}

\author{
C Pike, BComm Path; M Pike, BComm Path; A Kritzinger, DPhil; E Krüger, MComm Path; M Viviers, MComm Path
}

Department of Speech-Language Pathology and Audiology, Faculty of Humanities, University of Pretoria, South Africa

Corresponding author: E Krüger (esedra.kruger@up.ac.za)

\begin{abstract}
Background. Infants in neonatal intensive care are at risk of swallowing difficulties, in particular oropharyngeal dysphagia (OPD) and oesophageal dysphagia (OD). OPD is treated by speech-language therapists while OD is managed by doctors. Diagnosis of dysphagia is a challenge as equipment for instrumental evaluations is not readily available. Additional information to guide clinical assessment may be valuable.

Objective. To determine whether risk profiles of infants ( $\geq 32$ weeks' gestation) in a neonatal intensive care unit (NICU) and diagnosed with OPD or OD were distinctly different from one another.

Methods. Non-probability convenience sampling was used to select 49 participants. Based on modified barium swallow (MBS) examinations, three groups of participants were identified: no dysphagia $(n=11)$, OPD $(n=13)$ and OD $(n=25)$. Clinical data were collected to investigate associations between risk profiles and type of dysphagia.

Results. Factors such as gestational age, birth weight, poor weight gain and Apgar scores showed no association with either type of dysphagia in the sample of infants with a mean gestational age of 35.53 weeks. Increased NICU stay, increased chronological age, problematic breastfeeding and use of tube feeding showed an association with OPD. Three risk factors, namely intrauterine growth restriction, premature rupture of membranes and nutritive sucking difficulties were associated with OD.

Conclusion. Risk profiles associated with the two types of dysphagia may guide NICU personnel and speech-language therapists, especially in settings where no MBS equipment is available.
\end{abstract}

S Afr J Child Health 2016;10(2):130-133. DOI:10.7196/SAJCH.2016.v10i2.1051

Assessment of paediatric dysphagia is a challenge, particularly in hospitals where equipment for instrumental evaluation is not readily available. Diagnosis of dysphagia is often based solely on clinical evaluations, which may fail to accurately identify difficulties in the swallowing mechanism that would otherwise be identifiable with instrumental evaluation such as modified barium swallow (MBS) examinations. ${ }^{[1]}$ Since successful feeding is one of the criteria for discharge from a neonatal intensive care unit (NICU), ${ }^{[2]}$ any additional information that may guide clinical assessment is therefore important. Paediatric dysphagia can occur as a result of preterm birth and low birth weight, and other medical and developmental conditions ${ }^{[3,4]}$ Knowledge of risks associated with different types of dysphagia, such as oropharyngeal dysphagia (OPD) and oesophageal dysphagia (OD), may not only guide speech-language therapists and doctors, but will be valuable to personnel in a NICU by assisting early identification and referral. OPD is treated by speech-language therapists while OD is managed by doctors. Early identification of dysphagia in infants is critical, as secondary complications such as aspiration pneumonia, failure to thrive, gastro-oesophageal reflux (GOR) as well as insufficient nutrition and hydration, may arise. ${ }^{[5]}$ Interference with the nutritional requirements of infants may cause negative psychological consequences for caregivers and even death in infants. ${ }^{[6]}$ The incidence of dysphagia is increasing, partially due to the improved survival of preterm infants and those with complex medical conditions. ${ }^{[4]}$ Studies associate preterm birth and related complications, such as necrotising enterocolitis, respiratory distress syndrome (RDS), tachypnoea and apnoea, bronchopulmonary dysplasia (BPD) with dysphagia. ${ }^{[3-5]}$ Primary difficulty in swallowing in preterm infants may be due to neurodevelopmental immaturity. ${ }^{[7]}$ Literature on the risks associated with specific types of paediatric dysphagia is limited. Existing literature appears to focus on the prevalence of types of dysphagia within specific conditions, rather than identifying specific risks associated with each type of dysphagia. Lefton-Greif et al.. ${ }^{[8]}$ however, explain that risks for OPD in infants include preterm birth, gastrointestinal tract and airway abnormalities, central nervous system impairments, neurodevelopmental delay and syndromes affecting craniofacial structures. Conditions associated with OD appear to be mainly GOR, which may also be associated with preterm birth. ${ }^{[2]}$ Since preterm birth is a known risk for both OPD and OD, studying dysphagia in infants of $\geq 32$ weeks' gestation may identify risks other than preterm birth.

\section{Methods}

A three-group comparative study design was used. MBS data were prospectively collected and participants were assigned to the categories OPD, OD and no dysphagia. The study was conducted in a 29-bed NICU and high care in an urban, tertiary-care hospital, where expressed breastmilk via cup feeding followed by breastfeeding is promoted. Non-probability convenience sampling ${ }^{[9]}$ was used to select as many participants as possible within the study's time limit. Prospective participants could be of any gender, present with any neonatal condition, but had to be $\geq 32$ weeks' gestational age and in the NICU or high care. The sample included 49 participants with slightly more males $(n=26 ; 53 \%)$ than females $(n=23 ; 47 \%)$. The mean birth weight was $2.11 \mathrm{~kg}$ (standard deviation (SD) $0.74 \mathrm{~kg}$; range 0.95 - $3.64 \mathrm{~kg}$ ). The mean gestational age was 35.53 (SD 2.95; range 32 42) weeks. The participants' chronological age at data collection was 10.73 (SD 9.36; range 2 - 49) days.

A risk assessment checklist ${ }^{[10]}$ was used to record pre- and perinatal risks. A neonatal feeding assessment scale was used to observe feeding performance. MBS examinations were conducted in the lateral view to diagnose the presence and type of dysphagia. A SYSCO 
19' version Multi DiagnostEleva FD screening machine (Philips, Netherlands/Holland) was used. The classification of dysphagia was guided by symptoms described by Arvedson and Brodsky. ${ }^{[2]}$ The following symptoms were considered indicative of OPD: poor bolus formation, liquid spilling from the mouth, liquid adhering to the tongue or hard palate or that entered the sulci, piecemeal deglutition, delayed oral and/or pharyngeal transit time, aspiration before/after swallowing, pooling in the valleculae and pyriform sinuses and/ or pharyngeal recesses, velopharyngeal incoordination, reduced pharyngeal motility and laryngeal penetration. OD symptoms included cricopharyngeal dysfunction, reduced oesophageal motility, GOR, tracheo-oesophageal fistula, oesophagitis and obstruction of the oesophagus. ${ }^{[2]}$

Ethical clearance was granted by the Faculty of Health Sciences and the Faculty of Humanities of the University of Pretoria. Informed consent was obtained from all parents. Data were collected by a qualified speech-language therapist and three undergraduate speech- language therapy students trained in the procedures. Participants medical records were reviewed and a structured interview was conducted with the parents. Thereafter, the mothers were observed feeding their infants. All participants were scheduled for an MBS examination within 8 days of initial contact. Data were collected prospectively until at least ten participants with no dysphagia were included as to allow statistical comparison between the three groups. MBS examinations were performed by two independent speech-language therapists experienced in the procedure in infants. The MBS team was blind to the participants' medical history and feeding observations. The MBS procedure was conducted according to recommendations for paediatric assessments. ${ }^{[2]}$ Infants were positioned in a stable position at $45^{\circ}$, and a thin barium mixture was presented in a bottle. Participants with positive MBS results received feeding intervention. Data from the three groups of participants were analysed. Association of discrete risk factors and dysphagia were determined using the Fisher's exact test

Table 1. Discrete data of risks associated with different types of dysphagia

\begin{tabular}{|c|c|c|c|c|c|c|c|c|c|}
\hline & Risk factor & $\begin{array}{l}\text { Normal }(n=11) \text {, } \\
\%(n)\end{array}$ & $\begin{array}{l}\text { OD }(n=25) \\
\%(n)\end{array}$ & $\begin{array}{l}\text { OPD }(n=13) \\
\%(n)\end{array}$ & $\begin{array}{l}\text { Fisher's exact } \\
p \text {-value }\end{array}$ & $\begin{array}{l}\text { Dysphagia } \\
\text { type }\end{array}$ & RRR & $95 \% \mathrm{CI}$ & $p$-value \\
\hline \multirow{6}{*}{$\begin{array}{l}\text { Prenatal } \\
\text { and } \\
\text { delivery } \\
\text { factors }\end{array}$} & \multirow[t]{2}{*}{ IUGR } & \multirow[t]{2}{*}{$18.20(2)$} & \multirow[t]{2}{*}{$56.00(14)$} & \multirow[t]{2}{*}{$53.90(7)$} & \multirow[t]{2}{*}{0.089} & OD & 5.73 & $1.02-32.10$ & $0.047^{\star}$ \\
\hline & & & & & & OPD & 5.25 & $0.80-34.43$ & 0.084 \\
\hline & \multirow[t]{2}{*}{ C-section } & \multirow[t]{2}{*}{$63.60(7)$} & \multirow[t]{2}{*}{$68.00(17)$} & \multirow[t]{2}{*}{$30.80(4)$} & \multirow[t]{2}{*}{0.091} & OD & 1.21 & $0.27-5.38$ & 0.798 \\
\hline & & & & & & OPD & 0.25 & $0.05-1.39$ & 0.114 \\
\hline & \multirow[t]{2}{*}{ Preterm PROM } & \multirow[t]{2}{*}{$36.40(4)$} & \multirow[t]{2}{*}{$4.00(1)$} & \multirow[t]{2}{*}{$15.40(2)$} & \multirow[t]{2}{*}{$0.030^{*}$} & OD & 0.07 & $0.01-0.76$ & $0.029^{*}$ \\
\hline & & & & & & OPD & 0.32 & $0.05-2.22$ & 0.248 \\
\hline $\begin{array}{l}\text { Respiratory } \\
\text { factors }\end{array}$ & $\begin{array}{l}\text { Respiratory } \\
\text { support }\end{array}$ & $9.09(1)$ & $0(0)$ & $23.08(3)$ & $0.036^{*}$ & \multicolumn{4}{|c|}{ Insufficient data for further analysis } \\
\hline $\begin{array}{l}\text { Perinatal } \\
\text { conditions } \\
\text { and } \\
\text { treatment }\end{array}$ & $\begin{array}{l}\text { Neonatal } \\
\text { convulsions }\end{array}$ & $0(0)$ & $0(0)$ & $15.40(2)$ & 0.113 & \multicolumn{4}{|c|}{ Insufficient data for further analysis } \\
\hline \multirow{11}{*}{$\begin{array}{l}\text { Feeding } \\
\text { and related } \\
\text { factors }\end{array}$} & $\begin{array}{l}\text { Fussy during } \\
\text { feedings }\end{array}$ & $0(0)$ & $0(0)$ & $15.38(5)$ & 0.118 & \multicolumn{4}{|c|}{ Insufficient data for further analysis } \\
\hline & $\begin{array}{l}\text { Breathing } \\
\text { difficulties } \\
\text { during/after } \\
\text { feeding }\end{array}$ & $0(0)$ & $0(0)$ & $15.38(2)$ & 0.118 & \multicolumn{4}{|c|}{ Insufficient data for further analysis } \\
\hline & $\begin{array}{l}\text { Rooting reflex } \\
\text { present }\end{array}$ & $100(11)$ & $66.67(16)$ & $76.92(10)$ & 0.097 & \multicolumn{4}{|c|}{ Insufficient data for further analysis } \\
\hline & \multirow[t]{2}{*}{ Feeding tube } & \multirow[t]{2}{*}{$27.27(3)$} & \multirow[t]{2}{*}{$33.33(8)$} & \multirow[t]{2}{*}{$76.92(10)$} & \multirow[t]{2}{*}{$0.020^{*}$} & OD & 1.33 & $0.28-6.44$ & 0.72 \\
\hline & & & & & & OPD & 8.89 & $1.40-56.57$ & $0.021^{*}$ \\
\hline & $\begin{array}{l}\text { Problematic } \\
\text { breastfeeding }\end{array}$ & $20.00(2)$ & $5.26(1)$ & $63.64(7)$ & $0.002^{*}$ & OD & 0.22 & $0.02-2.82$ & 0.246 \\
\hline & Choking & $0(0)$ & $20.83(5)$ & $53.85(7)$ & $0.007^{*}$ & Insufficient $\mathrm{d}$ & ta for $\mathrm{f}$ & irther analysis & \\
\hline & $\begin{array}{l}\text { Positing of milk } \\
\text { during/after } \\
\text { feeding }\end{array}$ & $0(0)$ & $12.50(3)$ & $38.46(5)$ & $0.034^{*}$ & Insufficient $\mathrm{d}$ & ta for $\mathrm{f}$ & irther analysis & \\
\hline & $\begin{array}{l}\text { Hyperextension } \\
\text { during feeding }\end{array}$ & $0(0)$ & $0(0)$ & $23.08(3)$ & $0.026^{*}$ & Insufficient d & ta for $\mathrm{f}$ & Irther analysis & \\
\hline & Nutritive sucking & $36.36(4)$ & $75.00(18)$ & $41.67(5)$ & $0.042^{\star}$ & OD & & $.13-24.42$ & $0.034^{\star}$ \\
\hline & ditticulties & & & & & OPD & & $.23-6.71$ & 0.795 \\
\hline
\end{tabular}


and the relative risk ratio (RRR) from a multinomial logistic regression. Although the sample was small, it was deemed valuable to identify which dysphagia type (OPD or OD) showed a significant association with a certain risk factor. Differences between OPD and OD and continuous risk factors were assessed using a one-way analysis of variance (ANOVA). Following the ANOVA, a pair-wise comparison was conducted with Bonferroni adjustments. Associations of $\geq 0.05$ were deemed significant.

\section{Results}

From the total of 49 participants, $11(22.5 \%)$ infants had no dysphagia, while $13(26.5 \%)$ presented with OPD and the majority had OD ( $n=25$ or $51 \%)$. Potential risks were grouped into categories that were kept constant across two tables, with Table 1 indicating discrete data and Table 2 showing continuous data tested for associations. Factors that showed no significance in this sample of participants with a mean gestational age of 35.53 weeks, included gestational age, birth weight, poor weight gain, number of days in incubator, Apgar score, meconium aspiration, RDS, patent ductus arteriosus and other congenital heart conditions, intraventricular haemorrhage, meningitis, septicaemia, hyperbilirubinaemia, congenital conditions such as craniofacial deformities, slow feeding, increased duration of tube feeding, refusing feeds and gagging and vomiting. It could be that the sample was too small to indicate correlations between some of these conditions and OPD and OD.

\section{Prenatal and delivery factors}

A statistically significant correlation between intrauterine growth restriction (IUGR) and OD $(p=0.047)$, premature rupture of membranes (PROM) and OD $(p=0.029)$ was found (Table 1). The RRR indicated that participants with OD were 5.73 more times likely to present with IUGR.

\section{Perinatal factors}

Participants with OPD were significantly older $(p=0.007)$ and remained longer in the NICU $(p=0.003)$ than those without dysphagia (Table 2). Both these findings were supported by significant Bonferroni adjustments. Statistically significant associations between the three groups of dysphagia with regard to respiratory support and medications received (Table 1 ) could not be analysed further as data were not sufficient.

\section{Feeding and related factors}

Statistically significant results were found for the remainder of feeding and related characteristics: Participants with OPD were likely to be fed via feeding tubes $(p=0.02)$ and experience difficulties with breastfeeding
Table 2. Continuous data of risks associated with different types of dysphagia

\begin{tabular}{lllll}
\hline Risk factor & Groups & Mean (SD) & $\begin{array}{l}\text { Fisher's exact } \\
\boldsymbol{p} \text {-value }\end{array}$ & $\begin{array}{l}\text { Results after Bonferroni } \\
\text { adjustments, compared with } \\
\text { no dysphagia }\end{array}$ \\
\hline $\begin{array}{l}\text { Chronological } \\
\text { age (days) }\end{array}$ & Normal & $5.73(3.07)$ & $0.004^{*}$ & - \\
& OD & $10.20(8.01)$ & & 0.084 \\
& OPD & $16.00(12.70)$ & & $0.003^{*}$ \\
Days in NICU & Normal & $5.73(3.04)$ & $0.01^{*}$ & - \\
& OD & $9.54(7.20)$ & & 0.118 \\
& OPD & $15.31(12.98)$ & & $0.007^{*}$ \\
$*$ Statistically significant. & & &
\end{tabular}

Table 3. Risk factors according to types of dysphagia

Factors associated with OPD

Factors associated with OD

Increased chronological age

Increased stay in the NICU

Tube feeding

Problematic breastfeeding

IUGR

Nutritive sucking difficulties

Preterm PROM

$(p=0.002)$. Results showed that nutritive sucking difficulties were significantly associated with OD $(p=0.042)$. According to Table 1, both types of dysphagia were associated with choking $(p=0.007)$, positing of milk ( $p=0.034)$ and hyperextension during feeding ( $p=0.026$ ). Due to insufficient data only some risks for feeding could be analysed further and were found to differentiate between OPD and OD. The RRR for tube feeding and breastfeeding difficulties were strong, indicating that participants with OPD were 8.89 times more likely to be fed with a tube and 7 times more likely to experience breastfeeding difficulties. The RRR indicated that participants with OD were 5.25 times more likely to present with nutritive sucking difficulties.

\section{Discussion}

In this sample of 49 participants, 51\% presented with OD and $26.5 \%$ presented with OPD. When compared with an MBS diagnosis of OD or OPD, only a few clinical factors were found to be significantly associated with the two types of dysphagia in the sample of mostly late preterm infants (mean gestational age 35.53 weeks). The participants with OPD were in the NICU for longer and were older than participants with OD and no dysphagia. The correlation between increased time in the NICU and increased chronological age with both types of dysphagia is logical as infants that are seriously ill and born preterm may require longer hospitalisation..$^{[2]}$ These two seemingly similar risk factors (days in NICU and chronological age) differ, as some infants may have been born before arrival at the hospital and would therefore have spent fewer days in NICU than their age in days. The results show that those with dysphagia were not discharged early from the NICU. The purpose of early dysphagia intervention would be to prevent a lengthy NICU stay. OPD was also associated more with tube feeding than OD. While tube feeding is often the initial approach to manage feeding difficulties, it can also prolong dysphagia in preterm infants, delay treatment, negatively influence oral feeding and may increase GOR. ${ }^{[2,11]}$ Problematic breastfeeding was associated more with OPD. This is consistent with the various symptoms that may be present during feeding of an infant with dysphagia. ${ }^{[2,5]}$ Hyperextension during feeding influences the alignment of pharyngeal structures and places infants at risk for aspiration, a symptom of OPD ${ }^{[2]}$ Stressful mealtimes and fussiness are associated with dysphagia. ${ }^{[5]}$ IUGR was associated with OD, indicating that the smaller the infant, the more likely it will present with dysphagia. Infants born small-for-gestational age are at increased risk of respiratory illnesses, including BPD and RDS, and longer use of ventilator support and oxygen supplementation. ${ }^{[12]}$ The frequency of GOR, a condition associated with OD, is increased in infants with BPD due to an increase in positive abdominal pressure. ${ }^{[13]}$ BPD and RDS have a known association with dysphagia, ${ }^{[3-5]}$ which may further explain this result. Participants with OD were significantly more likely to present clinically with nutritive sucking difficulties than those with OPD, which is in itself a symptom of possible OPD. The reason for not observing sucking difficulties in participants with OPD may be that $76.92 \%$ of those with OPD were feeding 
via a tube (Table 1), thereby masking any sucking difficulties that may have been present. Only $33.33 \%$ of participants with OD were feeding via a tube, thereby allowing observations of nutritive sucking in more infants than in the OPD group. PROM is associated with OD in the sample, which may indicate an indirect risk. Preterm PROM accounts for $30-40 \%$ of preterm births and is associated with RDS in infants, ${ }^{[14]}$ both of which have been associated with dysphagia. Both IUGR and nutritive sucking difficulties possibly indicate maturational problems found in participants with OD. It has been suggested that GOR, a condition associated with OD, is often a consequence of lower oesophageal sphincter immaturity. ${ }^{[13]}$ Table 3 provides a summary of statistically significant factors associated with OD and OPD. The small sample size and the exclusion of extremely preterm neonates from the sample could have contributed to the few associations found.

\section{Conclusion}

Apart from preterm birth, OPD and OD showed distinct risk profiles that were tested against the MBS results of dysphagia in this sample of mostly late preterm infants. Although an MBS is the ideal, knowledge of the risk profiles of OPD and OD may enable personnel and speech-language therapists in the NICU and high care to identify, assess and treat infants with dysphagia timeously. Risk factors found in this study may be used as a starting point for the development of an instrument to assist in the early identification of dysphagia, which would be valuable in resource-poor settings. A larger sample is required to determine if the data can be used to indicate OPD and OD in other clinical settings.

\section{References}

1. DeMatteo C, Matovich D, Hjartarson A. Comparison of clinical and videofluoroscopic evaluation of children with feeding and swallowing difficulties. Dev Med Child Neurol 2005;47(3):149-157. DOI:10.1111/j.1469-8749.2005.tb01108.x

2. Arvedson JC, Brodsky L. Pediatric Swallowing and Feeding: Assessment and Management. New York: Thomson Delmar Learning, 2002.

3. Groher ME, Crary MA. Dysphagia: Clinical Management in Adults and Children. Maryland Heights: Mosby Elsevier, 2009:50-71.

4. Miller CK. Updates on pediatric feeding and swallowing problems. Curr Opin Otolaryngol Head Neck Surg 2009;17(3):194-199. DOI:10.1097/ MOO.0b013e32832b3117

5. Prasse JE, Kikano GE. An overview of pediatric dysphagia. Clin Pediatr 2009;48(3):247-251. DOI:10.1177/0009922808327323

6. Barratt J, Ogle V. Recorded incidence and management of dysphagia in an outpatient paediatric neurodevelopmental clinic. S Afr J Child Health 2010;4(2):38-41. DOI:10.7196/sajch.223

7. Heuschkel RB, Fletcher K, Hill A, Buonomo C, Bousvaros A, Nurko S. Isolated neonatal swallowing dysfunction: A case series and review of the literature. Dig Dis Sci 2003;48:30-35.

8. Lefton-Greif MA, Carroll JL, Loughlin GM. Long-term follow-up of oropharyngeal dysphagia in children without apparent risk factors. Pediatr Pulmonol 2006;41(11):1040-1048. DOI:10.1002/ppul.20488

9. Leedy PD, Ormrod JE. Practical Research: Planning and Design. 10th ed. New Jersey: Pearson Education, 2014:190-231.

10. Kritzinger A. Vroeë kommunikasieontwikkeling van biologiese risikobabas. Masters dissertation. Pretoria; University of Pretoria, 1994.

11. Bingham PM. Deprivation and dysphagia in premature infants. J Child Neurol 2009;24(6):743-749. DOI:10.1177/0883073808329530

12. Qiu X, Lodha A, Shah PS, et al. Neonatal outcomes of small for gestational age preterm infants in Canada. Am J Perinatol 2012;29(2):87-94. DOI:10.1055/s-0031-1295647

13. Wolf LS, Glass RP. Feeding and Swallowing Disorders in Infancy. Assessment and Management. Tucson: Therapy Skill Builders, 1992:297-398.

14. Rogers B, Arvedson J. Assessment of infant oral sensorimotor and swallowing function. Ment Retard Dev Disabil Res Rev 2005;11(1):74-82. 